\title{
MANEJO DE RESÍDUOS DE DEMOLIÇÃO GERADOS DURANTE OBRAS DA ARENA DE FUTEBOL PALESTRA ITÁLIA (ALLIANZ PARQUE) LOCALIZADA NA CIDADE DE SÃO PAULO/BRASIL
}

\author{
João Alexandre Paschoalin Filho ${ }^{1}$, Antonio Jose Guerner Dias, Pedro Luis Cortes e Eric Brum Lima Duarte \\ E-mail: jalexandre@uninove.br ${ }^{1}$
}

Artigo submetido em julho/2013 e aceito em dezembro/2013

\section{RESUMO}

Com o incremento do crescimento econômico brasileiro e, por consequência, do nível de atividade da construção civil, a geração de resíduos provenientes deste setor consiste em um importante problema a ser sanado. Formas de reaproveitamento destes resíduos, muitas vezes na composição de novos materiais, e o desenvolvimento de modelos e ferramentas de gestão têm sido a tônica de diversos trabalhos apresentados ao meio técnico no intuito de se mitigar os efeitos causados pelo impacto da construção civil no meio ambiente, tanto natural, quanto urbano. Contudo, a ausência de políticas públicas objetivas que considerem como problema real a geração, manuseio e deposição destes resíduos ainda se constituem como importantes empecilhos na adoção de práticas de sustentabilidade. Este trabalho apresenta os aspectos gerais do manejo de resíduos gerados por operações de demolição das obras de reforma da Arena Palestra Itália (Allianz Parque) localizada na cidade de São Paulo por meio de atividades de reciclagem e reuso destes materiais no canteiro das obras. Através dos parâmetros obtidos pôde-se observar que os resíduos produzidos foram predominantemente do tipo Classe A. A gestão dos resíduos produzidos na obra proporcionou ganhos econômicos significativos, uma vez em que foram reduzidos custos de transporte e aquisição de matérias primas naturais.

PALAVRAS-CHAVE: Resíduos de construção civil; impactos ambientais; plano de manejo de resíduos; reuso; sustentabilidade.

\section{WASTE MANAGEMENT OF DEMOLITION WORKS CREATED DURING THE PALESTRA ITÁLIA FOOTBALL ARENA (ALLIANZ PARK) LOCATED IN THE CITY OF SÃO PAULO/BRAZIL}

\begin{abstract}
With the increase of Brazilian economic growth and, consequently, the level of construction activity, the generation of residues from this sector is an important problem to be solved. Alternatives to recycle these residues, often in the composition of new materials, and developing models and management tools have been studied in several papers presented to the technical means in order to mitigate the effects caused by the impact of construction on the environment. However, the absence of public policies that consider the generation, handling and disposal of these wastes as a real problem, are still the biggest obstacle in the
\end{abstract}

adoption of sustainable practices. This paper presents the general aspects of the management of waste generated by construction operations and demolition works to reform the Palestra Italia Arena (Allianz Parque) in the city of São Paulo by means of activities of recycling and reuse of these materials on the construction site of the works. The management of the demolition wastes produced in the construction work allowed significant economic gains, reducing transportation costs and acquisition of natural raw materials. The great part of the total amount of waste produced could be characterized as Class A.

KEYWORDS: Civil construction wastes; environmental impacts; reuse; waste management plan; sustainability. 


\section{MANEJO DE RESÍDUOS DE DEMOLIÇÃO GERADOS DURANTE OBRAS DA ARENA DE FUTEBOL PALESTRA ITÁLIA (ALLIANZ PARQUE) LOCALIZADA NA CIDADE DE SÃO PAULO/BRASIL}

\section{INTRODUÇÃO}

Nos centros urbanos, responsáveis por agregar a maior parte da população, são muitos os sinais de impactos ao meio ambiente provocados pelo homem. O ritmo imposto pelo crescimento econômico aos diversos setores da cadeia produtiva e o consumo, cada vez mais barato e intenso, têm causado a geração de vultosas quantias de Resíduos Sólidos Urbanos (RSU). De uma forma geral, dentre os resíduos que compõem a massa de RSU gerada diariamente, grande parte destes se devem àqueles provenientes de atividades ligadas à construção civil. $O$ crescimento deste setor, que é fortemente alavancado pelo panorama econômico e a necessidade de se atender aos déficits habitacionais e de infraestrutura, é também responsável por uma considerável pegada ambiental, quer seja pela crescente demanda por matérias primas naturais, ou pela geração de resíduos durante a demolição de edifícios antigos ou execução novas obras.

Apesar de a construção civil ser considerada como um dos setores produtivos que mais causa impactos no meio ambiente, tanto urbano, quanto natural; este também pode ser caracterizado como um dos elos da cadeia produtiva que mais investe em inovação tecnológica e desenvolvimento de ferramentas de gestão e manejo de seus resíduos.

Devido aos grandes volumes gerados, os resíduos de construção e demolição têm merecido especial atenção de pesquisadores que buscam não apenas reduzir sua geração, mas também viabilizar a sua reutilização, reciclagem e manejo sustentável, buscando incrementar nestes materiais valor agregado de mercado.

Além de reduzir a demanda por recursos naturais, a utilização de resíduos de construção e demolição em novas obras ajuda a resolver o problema da destinação desses materiais. Ressaltase que uma considerável parte dos resíduos gerados por pequenas obras são muitas vezes depositados em áreas irregulares e, mesmo as grandes obras, que promovem a destinação de seus resíduos de forma correta, também encontram dificuldades e encontrar áreas devidamente preparadas e legalizadas para depositá-los.

Dessa forma, pretende-se com esta pesquisa apresentar um estudo a respeito do manejo e gestão dos resíduos de gerados durante as operações de demolição da Arena de Futebol Palestra Itália, atualmente denominada Allianz Parque, localizada na cidade de São Paulo/Brasil. É objeto de estudo deste artigo apresentar a caracterização e os volumes de resíduos gerados, a destinação destes e a economia conseguida pela aplicação de ferramentas simples de gestão e reuso dos resíduos na própria obra.

\section{REFERENCIAL TEÓRICO}

\subsection{A indústria da construção civil e a geração de resíduos}

A indústria da construção civil é também responsável por um consumo considerável de recursos naturais não renováveis, uma vez que muitos dos insumos utilizados na produção dos materiais de construção são obtidos pela extração em jazidas naturais para atender à demanda de mercado. De acordo com Segantini \& Wada (2011) a construção civil é uma atividade geradora 
de grandes volumes de resíduos, tendo como consequência enormes desperdícios de materiais nobres, como areia, pedra, madeira e cimento, entre outros. De acordo com Ulsen et al. (2010), cerca de $90 \%$ da massa total de resíduos de construção e demolição (RCD) gerada no Brasil e na Europa é composta por concretos, argamassas, solo e gesso.

Silva \& Fernandes (2012), apontam que o setor da indústria da construção civil consome cerca de $50 \%$ de todos os recursos naturais além de gerar volume elevado de resíduos; cerca de $60 \%$ do "lixo" que é produzido diariamente nas cidades tem origem do setor da construção civil. Além dos impactos causados pelo extrativismo, a construção civil também arca com o ônus de impor ao meio ambiente, outras formas de agressão, tais como: poluição do ar, poluição sonora, contaminação de solo, geração de resíduos etc. John \& Agopyan (2000), comentam que a quantidade de resíduos de construção e demolição gerada por habitante no Brasil varia entre 230 e $660 \mathrm{~kg} / \mathrm{hab} / \mathrm{ano}$. De acordo com dados da Associação Brasileira das Empresas de Limpeza Pública e Resíduos Especiais (ABRELPE, 2012) a quantidade per capta de resíduos de construção e demolição coletada, comparando-se os anos de 2010 e 2011 cresceu aproximadamente 7\%, ou seja, de 0,618 kg/hab/dia para 0,656 kg/hab/dia. Este incremento correspondeu a uma massa adicional de 7.195 toneladas/dia recolhida. Ainda segundo a ABRELPE (2012), a região CentroOeste destacou-se como aquela que apresenta o maior índice de coleta de resíduos de construção e demolição per capta, aproximadamente 0,966 kg/hab/dia. Dentre as regiões prospectadas, a região Norte apresentou o menor índice de coleta, ou seja, apenas 0,330 $\mathrm{kg} / \mathrm{hab} /$ dia. No município de São Paulo, o mais populoso do Brasil, a Prefeitura Municipal contabilizou em 2000 a partir dos dados obtidos por John\& Agopyan (2000) aproximadamente 280 kg/hab/ano. Schneider (2003) contabilizou cerca de 490 e 499 kg/hab. Em 2008 foram gerados cerca de 6 milhões de toneladas de RCD em São Paulo, o que equivale a uma taxa per capta de $520 \mathrm{~kg} / \mathrm{hab}$ naquele ano. Para o Brasil, as estimativas de John \& Agopyan (2000) conduziram a valores entre $230 \mathrm{~kg} / \mathrm{hab} / \mathrm{ano}$ e $760 \mathrm{~kg} / \mathrm{hab} / \mathrm{ano}$ com valor médio equivalente a $510 \mathrm{~kg} / \mathrm{hab} / \mathrm{ano}$.

\subsection{Classificação dos Resíduos de Construção e Demolição}

De acordo com a resolução CONAMA $n^{0} 307$ (Conselho Nacional do Meio Ambiente) e 5 de julho de 2002, os resíduos de construção e demolição recebem a seguinte denominação: "Resíduos da construção civil: são os provenientes de construções, reformas, reparo de demolições de obras de construção civil, e os resultantes da preparação e da escavação de terrenos, tais como: tijolos, blocos cerâmicos, concreto em geral, solos, rochas, metais, resinas, colas, tintas, madeiras e compensados, forros, argamassa, gesso, telhas, pavimento asfáltico, vidros, plásticos, tubulações, fiação elétrica etc., comumente chamados de entulhos de obras, caliça ou metralha."

Ainda, segundo a resolução CONAMA $n^{\circ} 307 / 2002$, os resíduos de construção e demolição podem ser classificados em quatro grupos. Em 2004, em complementação à resolução CONAMA $n^{0} 307 / 2002$, foi elaborada a resolução CONAMA n³ 348/2004, na qual foi incluído o amianto como pertencente à classe de resíduos perigosos. O Quadro 1 apresenta a classificação dos resíduos de construção de acordo com a resolução CONAMA $n^{\circ} 431 / 2011$, que alterou a classificação apresentada na resolução CONAMA n ${ }^{\circ} 307 / 2002$, alterando a classificação do Gesso de Classe $\mathrm{C}$ para Classe $\mathrm{B}$. 
Quadro 1 - Classificação dos resíduos de construção de acordo a resolução CONAMA n ${ }^{\circ}$ 431/2011.

\begin{tabular}{|c|c|c|}
\hline Classe & Origem & Tipo de resíduo \\
\hline Classe A & $\begin{array}{l}\text { São os resíduos reutilizáveis ou } \\
\text { recicláveis como agregados. }\end{array}$ & $\begin{array}{c}\text { De pavimentação e de outras obras de infraestrutura, inclusive } \\
\text { solos provenientes de operações de terraplenagem. } \\
\text { Da construção, demolição reformas e reparos de edificações } \\
\text { (componentes cerâmicos, tijolos, blocos, telhas e placas de } \\
\text { revestimento, concreto e argamassa). }\end{array}$ \\
\hline Classe B & $\begin{array}{l}\text { Resíduos recicláveis com outras } \\
\text { destinações. }\end{array}$ & $\begin{array}{l}\text { Plásticos, gesso, papel, papelão, metais, vidros, madeiras e } \\
\text { outros. }\end{array}$ \\
\hline Classe C & $\begin{array}{c}\text { Resíduos para os quais ainda } \\
\text { não foram desenvolvidas } \\
\text { tecnologias ou aplicações que } \\
\text { permitam a sua reciclagem ou } \\
\text { recuperação. }\end{array}$ & Não especificado pela resolução \\
\hline \multirow[b]{2}{*}{ Classe D } & $\begin{array}{c}\text { Resíduos perigosos oriundos de } \\
\text { processo de construção. }\end{array}$ & Tintas, solventes, óleos, amianto. \\
\hline & $\begin{array}{l}\text { Aqueles contaminado, oriundos } \\
\text { de demolições, reforma e } \\
\text { reparo, enquadrados como } \\
\text { classe I na NBR10004. }\end{array}$ & Clínicas radiológicas, instalações industriais e outros. \\
\hline
\end{tabular}

Anteriormente a promulgação da Resolução CONAMA no 307/2002, o Brasil dispunha da Norma Brasileira denominada de NBR 10.004 -"Resíduos Sólidos - Classificação", publicada pela Associação Brasileira de Normas Técnicas (ABNT) no ano de 1987, que servia referência quanto à classificação dos resíduos sólidos. Após a entrada em vigor da Resolução CONAMA n³07/2002 a NBR 10.004 de 1987 sofreu uma revisão e foi publicada novamente no ano de 2004 com alterações, complementações e atualizações que vinham de encontro com as questões ambientais e o desenvolvimento sustentável em discussão desde a sua primeira publicação. De acordo com a NBR 10.004/2004, os resíduos de construção civil são classificados como inertes, ou seja, Classe II-B, uma vez que estes não apresentam constituintes que quando solubilizados afetem os padrões de potabilidade da água.

\subsection{Destinação Final dos Resíduos de Construção e Demolição}

De acordo com o artigo 10 da resolução CONAMA $n^{\circ} 307 / 2002$, os resíduos de construção civil deverão ser destinados de acordo com o descrito no Quadro 2

Quadro 2 - Destinação do RCD de acordo com a resolução CONAMA n 307/2002

\begin{tabular}{|c|c|}
\hline Classe & Destinação \\
\hline Classe A & $\begin{array}{r}\text { Deverão ser reutilizados ou reciclados na forma de agregados, ou encaminhados a } \\
\text { áreas de aterro de resíduos da construção civil, sendo dispostos de modo a permitir a } \\
\text { sua utilização ou reciclagem futura. }\end{array}$ \\
\hline Classe B & $\begin{array}{r}\text { Deverão ser reutilizados, reciclados ou encaminhados a áreas de armazenamento } \\
\text { temporário, sendo dispostos de modo a permitir a sua utilização ou reciclagem futura. }\end{array}$ \\
\hline Classe C & $\begin{array}{r}\text { Deverão ser armazenados, transportados e destinados em conformidade com as } \\
\text { normas técnicas específicas. }\end{array}$ \\
\hline Classe D & Deverão ser armazenados, transportados, reutilizados e destinados em conformidade \\
com as normas técnicas específicas.
\end{tabular}

Fonte: Resolução CONAMA n ${ }^{\circ}$ 307/2002 
De acordo com o artigo 5o da resolução CONAMA n 307/2002 é função de Municípios e do Distrito Federal a elaboração de um Plano Integrado de Gerenciamento de Resíduos da Construção Civil. Neste plano deverão ser incorporados os seguintes itens: a) Programa Municipal de Gerenciamento de Resíduos da Construção Civil e b) Projetos de Gerenciamento de Resíduos da Construção Civil.

O artigo 60 da resolução CONAMA $n^{0} 307 / 2002$ informa que o Plano Integrado de Gerenciamento de Resíduos da Construção Civil deverá ser composto por:

I. As diretrizes técnicas e procedimentos para o Programa Municipal de Gerenciamento de Resíduos da Construção Civil e para os Projetos de Gerenciamento de Resíduos da Construção Civil a serem elaborados pelos grandes geradores, possibilitando o exercício das responsabilidades de todos os geradores.

II. O cadastramento de áreas, públicas ou privadas, aptas para recebimento, triagem e armazenamento temporário de pequenos volumes, em conformidade com o porte da área urbana municipal, possibilitando a destinação posterior dos resíduos oriundos de pequenos geradores às áreas de beneficiamento;

III. O estabelecimento de processos de licenciamento para as áreas de beneficiamento e de disposição final de resíduos;

IV. A proibição da disposição dos resíduos de construção em áreas não licenciadas;

V. O incentivo à reinserção dos resíduos reutilizáveis ou reciclados no ciclo produtivo;

VI. A definição de critérios para o cadastramento de transportadores;

VII. As ações de orientação, de fiscalização e de controle dos agentes envolvidos;

VIII. As ações educativas visando reduzir a geração de resíduos e possibilitar a sua segregação.

De acordo com os itens II à IV citados anteriormente, é de responsabilidade do município a disponibilização de áreas adequadas para destinação dos resíduos de construção e demolição, além de ações de fiscalização quanto à deposição inadequada destes resíduos. Entretanto, o que ocorre muitas vezes é que grandes volumes de entulho são depositados diariamente em locais não adequados em diversos municípios brasileiros, configurando-se esta situação em cena comum na rotina dos cidadãos. Ressalta-se que a prática de deposição destes resíduos em tais áreas, além de imprópria é ilegal.

Segundo Paschoalin Filho \& Graudenz (2012) Os resíduos de construção dispostos irregularmente poluem o solo, degradam paisagens e constituem em grave ameaça à saúde coletiva. $\mathrm{O}$ acúmulo destes resíduos torna-se nicho ecológico de diversas espécies de agentes patogênicos, tais como roedores, baratas, moscas, vermes, pernilongos, fungos, vírus, animais entre outros. Estes vetores biológicos podem ser responsáveis pela transmissão de doenças respiratórias, epidérmicas, viroses, intestinais etc.

Os resíduos provenientes das atividades de demolição e construção, em função de sua constituição física e volume, apresentam dificuldades para a destinação final. Esses não são aceitos em aterros sanitários e geralmente são acondicionados no meio ambiente urbano sob a forma de caçambas. Embora a responsabilidade pela destinação correta dos resíduos seja do gerador (público ou privado) de acordo com a resolução CONAMA $n^{\circ} 307 / 2002$, alguns geradores não respeitam essa determinação, causando situações de deposição desse material em vias públicas, terrenos baldios ou a beira de córregos. Essa degradação da paisagem urbana estimula a criação de pequenos lixões a céu aberto que contribuem para a proliferação de vetores de doenças e o entupimento dos sistemas de drenagem. (PASCHOALIN FILHO \& GRAUDENZ, 2012). 


\subsection{Pesquisas sobre reciclagem e reuso dos resíduos de construção e demolição}

O setor da construção civil, apesar de ser um setor que necessita de muita matéria prima, consiste em dos setores produtivos que mais aproveita os seus resíduos, transformando-os assim em subprodutos. Dentro da construção civil, a confeç̧ão de concretos é o setor que mais consome agregados, entretanto este segmento pouco utiliza os agregados reciclados. Segundo Souza et al. (2008) a reciclagem e o reaproveitamento dos RCD tem se destacado como alternativas ligadas aos conceitos de sustentabilidade, embutindo valor econômico nos materiais descartados nas obras de engenharia. Desta forma é atribuída a estes resíduos a condição de material nobre, ao invés de simplesmente lançá-los ao meio ambiente.

Em 2012 o SINDUSCON/SP (Sindicato da Construção Civil do Estado de São Paulo) publicou os resultados de um estudo realizado em suas filiais por todo Estado de São Paulo, totalizando 348 municípios. Tal estudo teve por objetivo verificar a situação dos municípios e das obras civis em relação ao manejo e gerenciamento dos resíduos de construção gerados. As Figuras 2 e 3 apresentam a porcentagem de empresas que declararam reciclar e que reutilizar os resíduos de construção em suas obras.

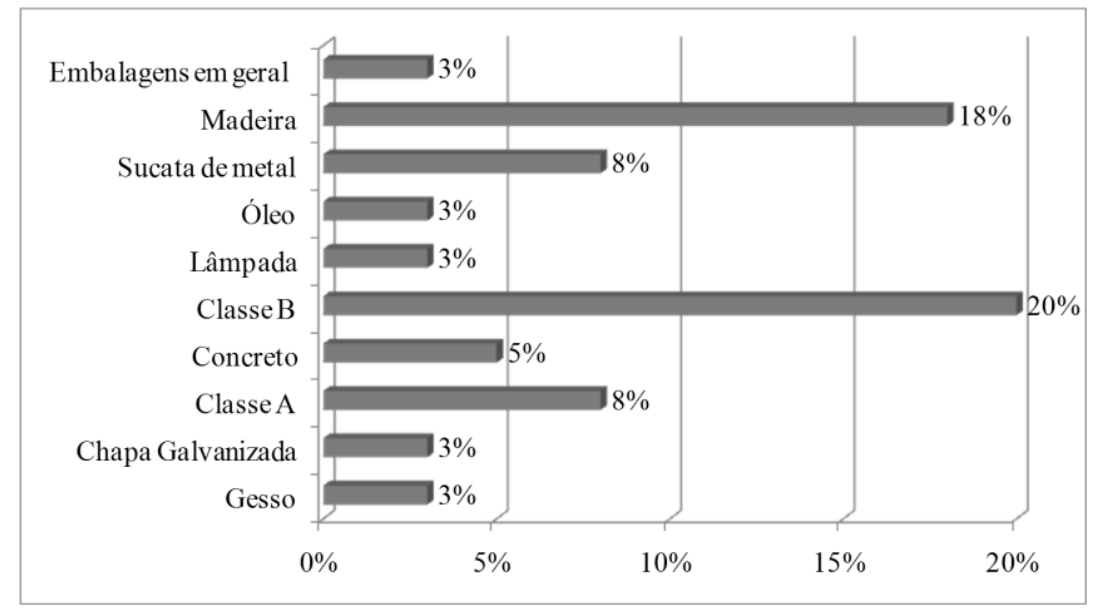

Figura 2. Porcentagem de empresas consultadas que reciclam os resíduos em suas obras. Fonte: Sinduscon (2012)

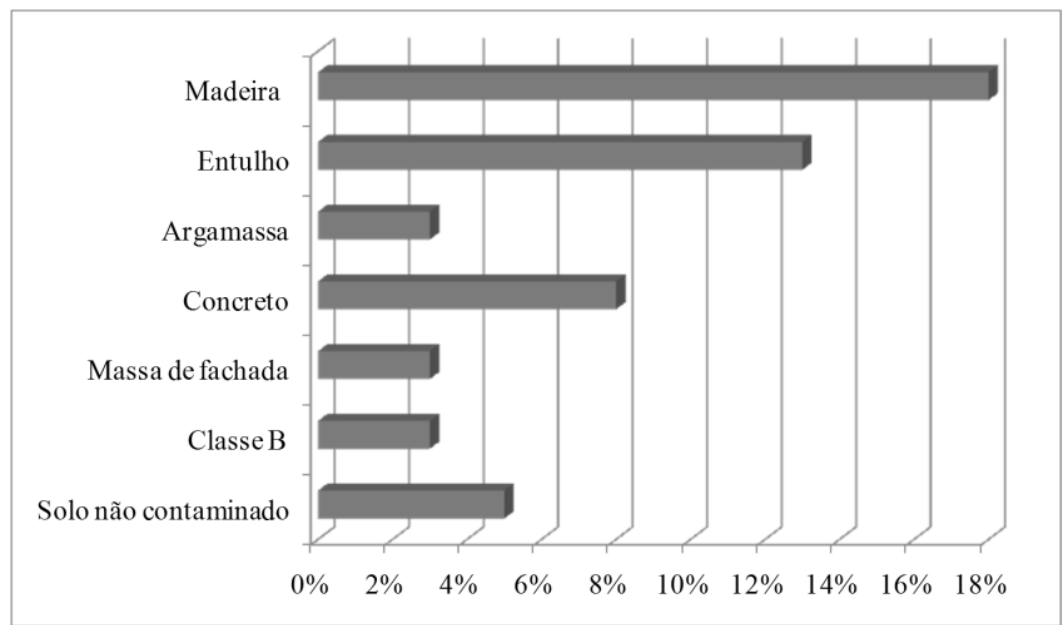

Figura 3. Porcentagem de empresas consultadas que reutilizam resíduos em suas obras. Fonte: Sinduscon (2012)

Observando-se a Figura 2 nota-se que maior parte das empresas consultadas (20\%) reciclam em suas obras resíduos de Classe $B$ (Plásticos, papel, papelão, metais, etc). Ressalta-se que mesmo sendo classificados como resíduos Classe B e A respectivamente, a madeira e o concreto foram analisados a parte dada a grande representatividade destes nos resultados 
obtidos. O SINDUSCON/SP (2012) também levantou quais os resíduos de construção as empresas prospectadas sofriam as maiores dificuldades de manejo e reuso. Dentre vários relatados destacaram-se como os mais citados pelas empresas: o Gesso (40\%), os resíduos Classe D (10\%), as latas de tinta (8\%) e os resíduos químicos (5\%).

Embora alguns municípios tenham problemas com a gestão dos RCD, eles constituem uma boa oportunidade de negócio (MELO et al., 2011). A análise dos RCD em municípios do interior do estado de São Paulo efetuada por Ângulo et al. (2011) mostrou a predominância de resíduos reutilizáveis ou recicláveis como agregados, correspondendo a 91\% em massa. Plásticos, papéis, metais, vidros e madeiras representam 9\%, não tendo sido verificados resíduos perigosos nesse estudo.

Os RCD são vistos ainda hoje pela sociedade como lixo que gera despesas, aumentando o custo final das obras. Porém, este "lixo" tem ganhado valor no mercado e o que antes era estorvo, está se tornando "moeda" de negociação em meio ao setor construtivo (SILVA \& FERNANDES, 2008).O Quadro 4 sintetiza os usos mais frequentes para os resíduos de construção e demolição, destacando as aplicações encontradas na literatura.

Quadro 4 - Usos mais frequentes para os RCC no Brasil

\begin{tabular}{|l|c|}
\hline \multicolumn{1}{|c|}{ Tipo de Uso } & \multicolumn{1}{|c|}{ Brasil } \\
\hline Agregados para concreto & (Vieira \& Molin, 2004) \\
\hline Produção de argamassa & (Assunção et al, 2007) \\
\hline $\begin{array}{l}\text { Em obras de pavimentação de estradas (como base } \\
\text { ou sub-base) ou calçadas }\end{array}$ & (Ricci, 2007) \\
\hline Obras de drenagem. & (Nunes et al, 2009) \\
\hline Estabilização de encostas & (Nunes et al, 2009) \\
\hline $\begin{array}{l}\text { Em algumas etapas nas obras de construção de } \\
\text { edifícios. }\end{array}$ & (Ferraz \& Segantini, 2004) \\
\hline $\begin{array}{l}\text { Tijolos (incluindo aqueles produzidos com solo- } \\
\text { cimento), telhas e blocos de concreto. }\end{array}$ & (Santos, 2007) \\
\hline $\begin{array}{l}\text { Como material de preenchimento, recuperação } \\
\text { topográfica do terreno ou em terraplenagem. }\end{array}$ & \\
\hline
\end{tabular}

Por meio do Quadro 4 pode-se observar que no Brasil o resíduo de construção e demolição pode ser reciclado para a utilização deste como agregado para concreto, na produção de argamassa e na manufatura de tijolos; ou também estes resíduos podem ser reutilizados de maneira direta como material de base em obras de terraplenagem, em obras de drenagem, estabilização de encostas ou como material de recuperação topográfica.

\section{METODOLOGIA UTILIZADA}

Esta pesquisa possui como principal objetivo apresentar um estudo acerca do manejo de resíduos produzidos durante as obras de demolição do Complexo Esportivo Arena Palestra Itália, atualmente conhecida como Allianz Parque. Com isto pretende-se ressaltar a importância da adoção de ferramentas de gestão sustentáveis no reaproveitamento destes resíduos por meio de sua reciclagem.

Para a realização deste trabalho e obtenção dos parâmetros necessários foi conduzida uma pesquisa de campo na qual teve por objeto de ação o estudo, acompanhamento e o levantamento de dados gerados durante a execução das obras de demolição da Arena Palestra Itália, localizada na cidade de São Paulo. 
De acordo com o procedimento de coleta de informações, esse trabalho pode ser caracterizado como estudo de caso, uma vez que um objeto de pesquisa restrito foi selecionado. Esta pesquisa também pode ser classificada como descritiva, já que os fatos acompanhados durante a execução das operações de demolição foram registrados e interpretados sem que os pesquisadores interferissem em seu andamento.

Os dados foram coletados a partir da consulta a documentos elaborados para fins de controle de saída dos resíduos produzidos pelas operações de demolição. Para tal foram utilizadas planilhas de controle de transporte de resíduos (CTR) geradas a cada saída de resíduo da obra. Por meio destas planilhas puderam-se quantificar os volumes descartados e os que remanesceram no empreendimento, bem como estimar os ganhos obtidos pelas operações de reciclagem e reuso dos materiais, além de possibilitar a verificação da economia em relação ao transporte e destinação dos resíduos para áreas adequadas e com a redução de necessidade de importação de matéria prima natural.

A emissão do CTR é obrigatória pela Legislação Federal e serve como controle para a destinação dos resíduos gerados. Ressalta-se que os resíduos gerados somente poderão ser recebidos nos locais de destino mediante a apresentação do CTR, pois por meio deste documento é possível apurar o local de geração, a empresa transportadora, a quantificação e o tipo do resíduo encaminhado.

\section{RESULTADOS E DISCUSSÕES}

\subsection{Caracterização do Local em Estudo}

A obra, objeto de estudo desta pesquisa, consiste nas operações de demolição ocorridas entre Janeiro e Dezembro de 2011 necessárias à construção da Arena Palestra Itália, atualmente denominada Allianz Parque, localizada no bairro da Água Branca, Município de São Paulo/SP e inserida nos limites da Subprefeitura da Lapa. A Figura 4 apresenta a localização da área em estudo.

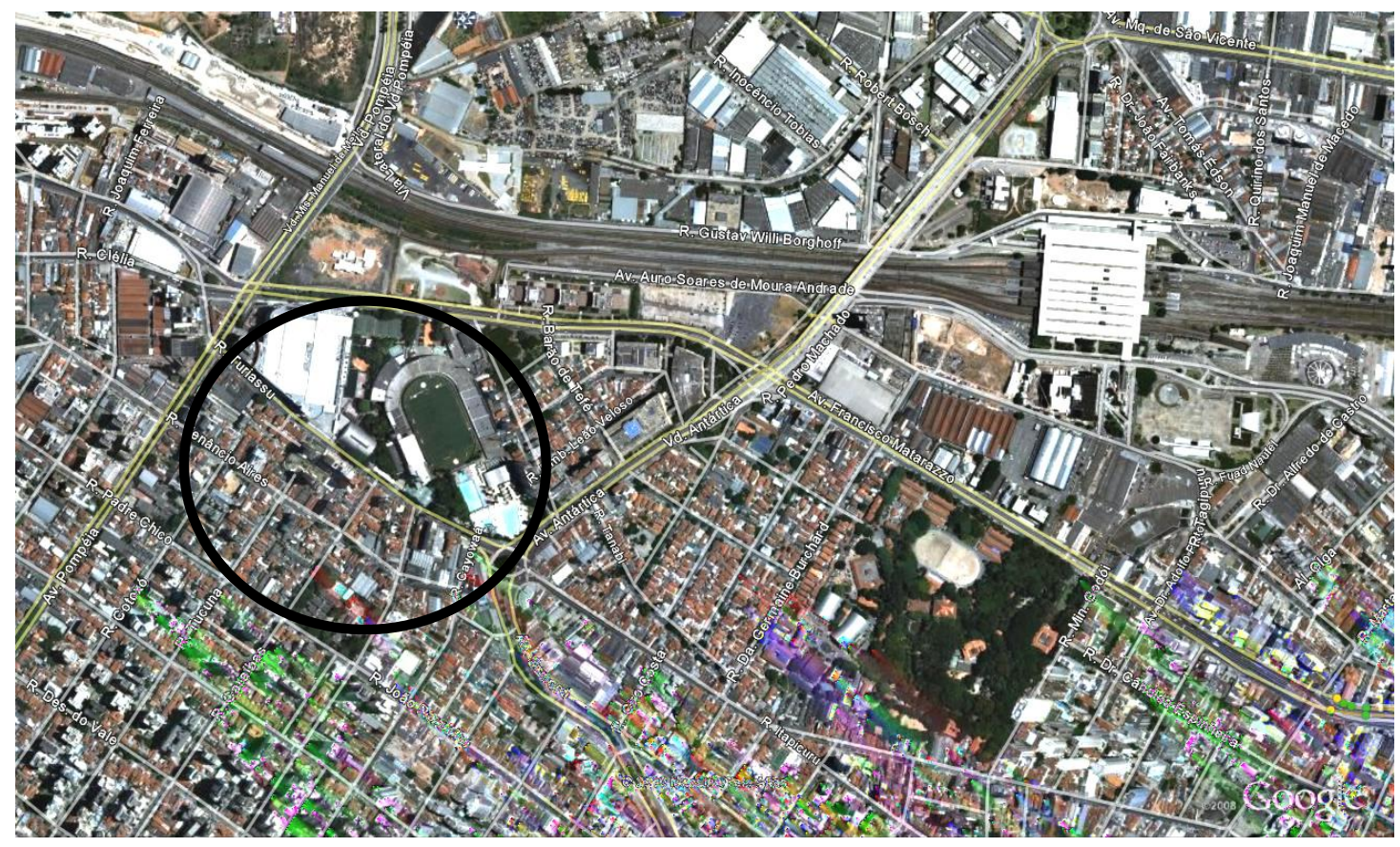

Figura 4. Localização do Complexo Esportivo Arena Palestra Itália antes da demolição. Fonte: Google Earth (2013) 
O projeto prevê a transformação do espaço em um pólo de atividades esportivas, além de contar com um centro de convenções, museu, estacionamento entre outras dependências.O estádio de futebol possuirá capacidade para 40.000 expectadores sentados em arquibancadas cobertas e descobertas atendendo as Normas Técnicas Oficiais - NTO e também as normas estabelecidas pela Fédération Internacionale de Football Association - FIFA. Este possuirá dois subsolos, um pavimento térreo e seis com área aproximada de $80 \mathrm{mil} \mathrm{m}^{2}$. A Figura 5 apresenta uma fotografia da maquete da obra após sua conclusão.

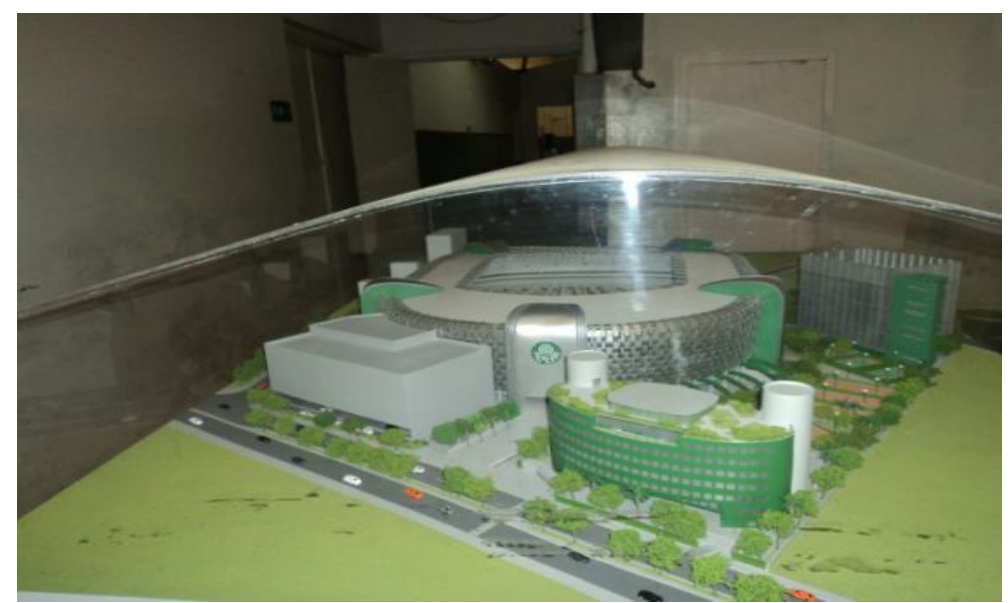

Figura 5. Maquete da obra finalizada. Fonte: Os Autores

\subsection{Caracterização e manejo dos Resíduos de Demolição gerados na obra}

Os resíduos de demolição produzidos no local em estudo foram identificados como sendo típicos daqueles encontrados em obras que envolvem, em sua primeira fase, demolição das construções existentes para a construção das novas edificações. Estes são geralmente compostos, em sua maioria, de resíduos cimentícios, cerâmicos, madeira, papel e metálicos, oriundos de estruturas de concreto, torres de iluminação e coberturas. Foram também verificados "in loco", em menores quantidades, resíduos orgânicos provenientes de podas e remoção de arvores. Os resíduos gerados puderam ser classificados como Classe A, o que, segundo a resolução CONAMA $n^{0} 307 / 2002$, consiste nos seguintes materiais: concreto, argamassa, alvenaria, solo, tijolo, telhas; e Classe B, ou seja, plásticos, papel, papelão, metais, vidros, madeiras e outros. Ressalta-se que grande parte dos resíduos gerados foi resultado da demolição da antiga estrutura do estádio, necessária para as obras de ampliação e modernização do local. A Figura 6 apresenta o aspecto de uma das arquibancadas após as operações de desmonte. 


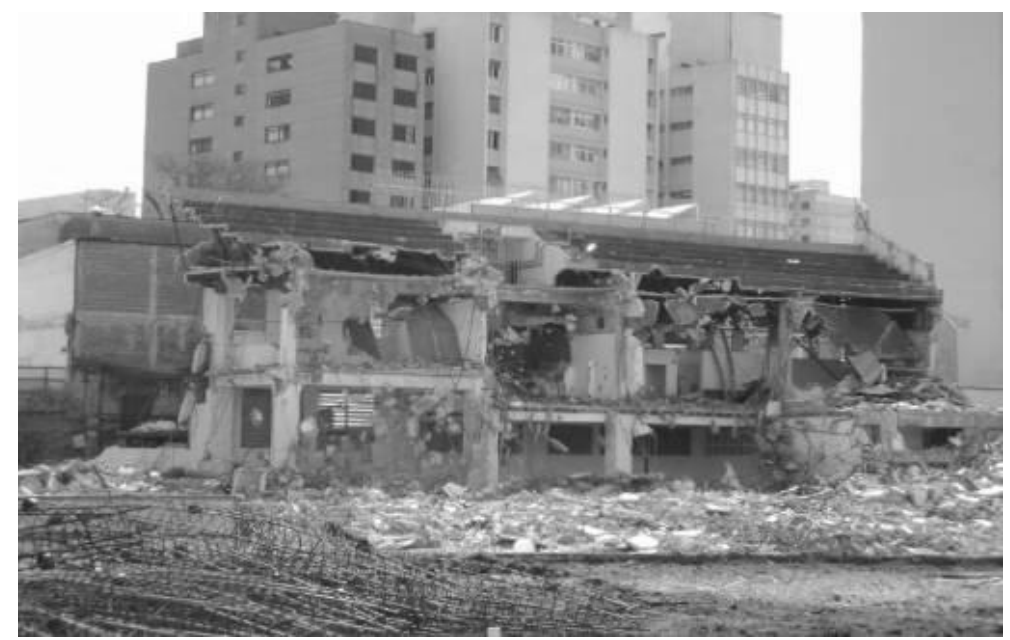

Figura 6. Aspecto da arquibancada após operação de desmonte. Fonte: Os Autores

Após a demolição das arquibancadas os resíduos provenientes desta operação foram transportados para uma usina móvel de britagem com capacidade de reciclagem de $400 \mathrm{~m}^{3} /$ hora, que foi instalada junto ao canteiro de obras, a fim de facilitar a logística de transporte dos materiais. A adoção de uma usina móvel "in loco" teve por finalidade facilitar e agilizar o processo de trituração dos resíduos deixando-os na granulometria desejada para posteriormente serem reutilizados na própria obra. A usina móvel era composta por um alimentador e uma unidade de britagem, que pode ser instalada em uma plataforma e ser deslocada até o canteiro da obra. As Figuras 7 e 8 apresentam a usina móvel em operação.

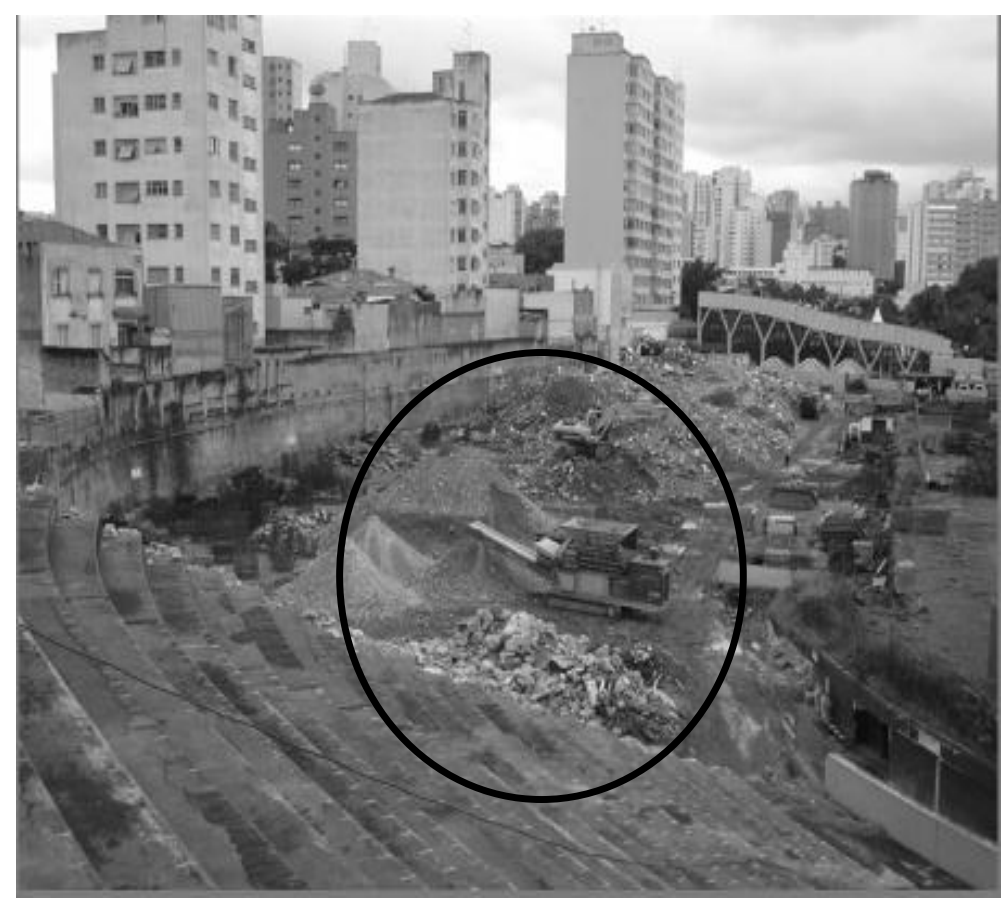

Figura 7. Usina móvel em operação. Fonte: Os Autores 


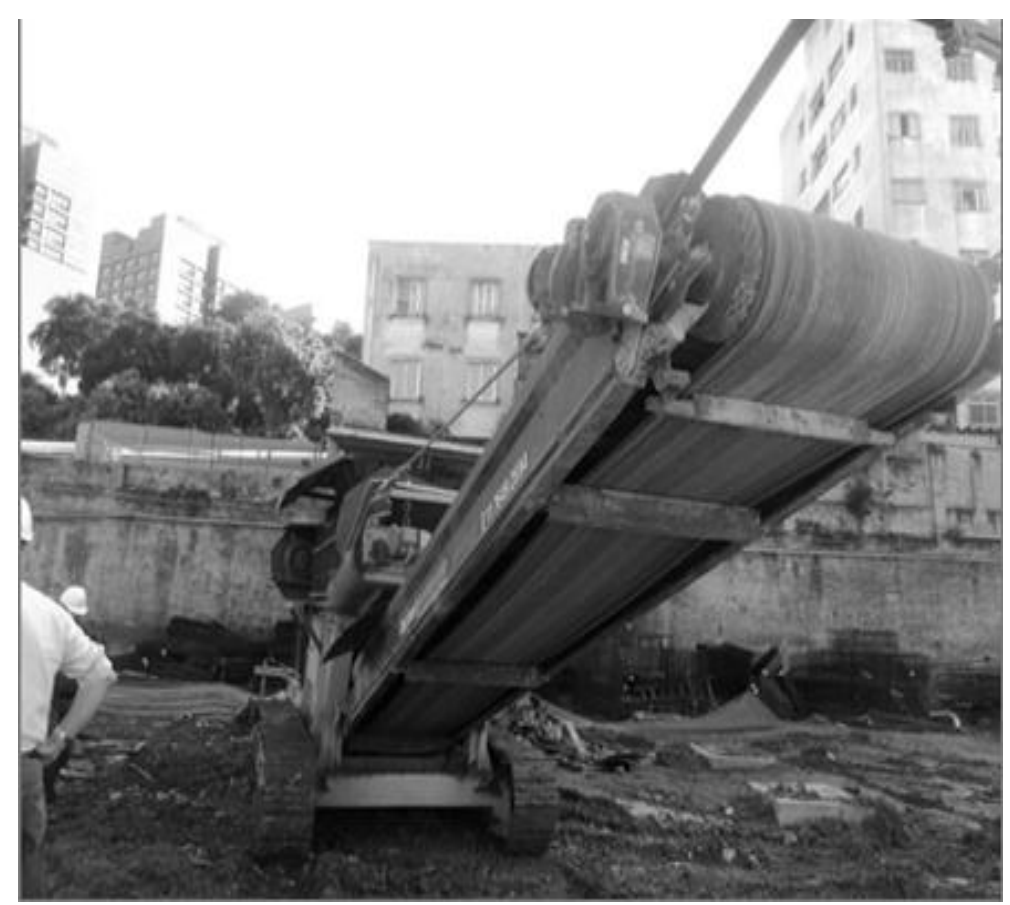

Figura 8. Usina Móvel utilizada. Fonte: Os Autores

Os resíduos reciclados "in loco" por meio da utilização da usina móvel foram reaproveitados na obra nas seguintes funções: a) utilização como base de pavimento, b) agregado para produção de argamassa e concreto não estrutural, c) aterro, e d) obras de drenagem superficial e profunda. Ressalta-se que o reuso dos resíduos, gerados na própria obra, diminuiu significativamente a necessidade de aquisição de matérias primas, além de reduzir os custos de transporte e deposição destes resíduos em áreas apropriadas. A Figura 9 apresenta o aspecto das pilhas de materiais reciclados pelas usinas móveis.

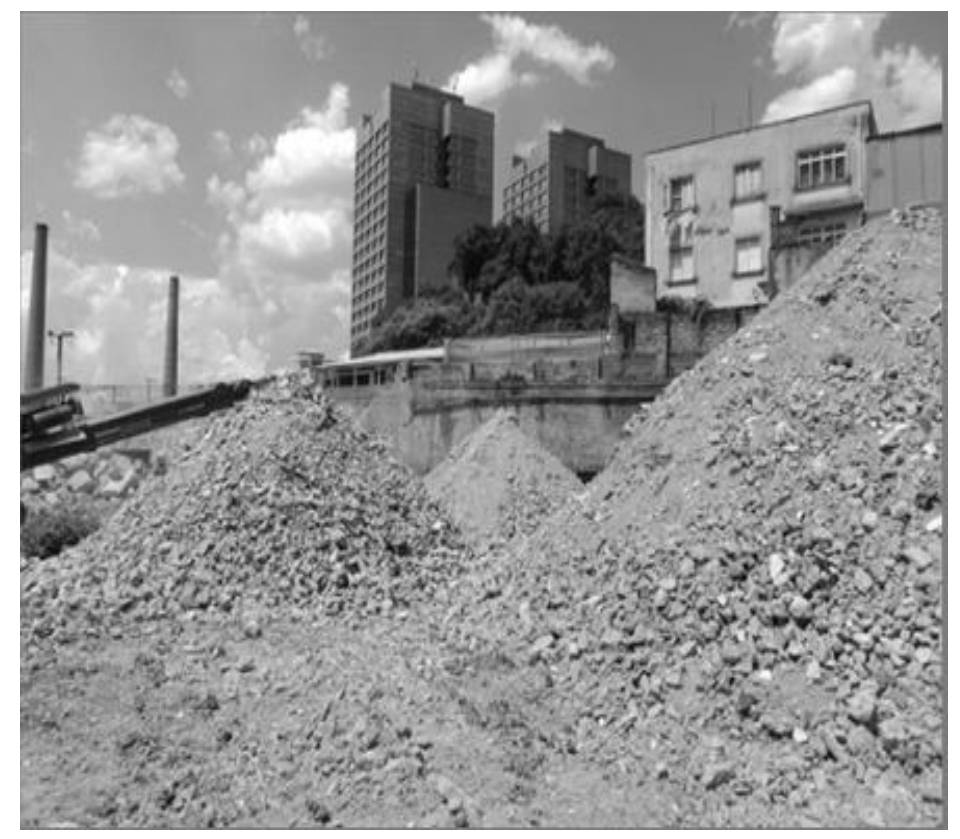

Figura 9. Pilha de materiais reciclados pela usina móvel. Fonte: Os Autores 
Desde o início das obras de demolição, de acordo com as aferições efetuadas "in loco", constatou-se que a maior parte do volume de resíduos gerados era proveniente de obras de terraplenagem, escavação e movimentação de solo em geral. Este volume atingiu o seu pico máximo entre os meses de março e abril de 2011, chegando a um valor de $11.586 \mathrm{~m}^{3}$, enquanto que a magnitude do volume composto pelos demais resíduos (Classe $A$, Classe $B$ ) atingiu, em seu máximo nível, $1.419 \mathrm{~m}^{3}$ no mês de maio, ou seja, inferior a $12 \%$ em relação ao volume gerado pela movimentação de terra. A Figura 10 apresenta a evolução dos volumes gerados de solo e dos demais resíduos produzidos na obra no período compreendido entre janeiro e dezembro de 2011. Deve ser salientado que mesmo pertencendo a Classe A de resíduos, o solo proveniente das operações de escavação e terraplenagem foi considerado a parte em função dos grandes volumes observados em campo.

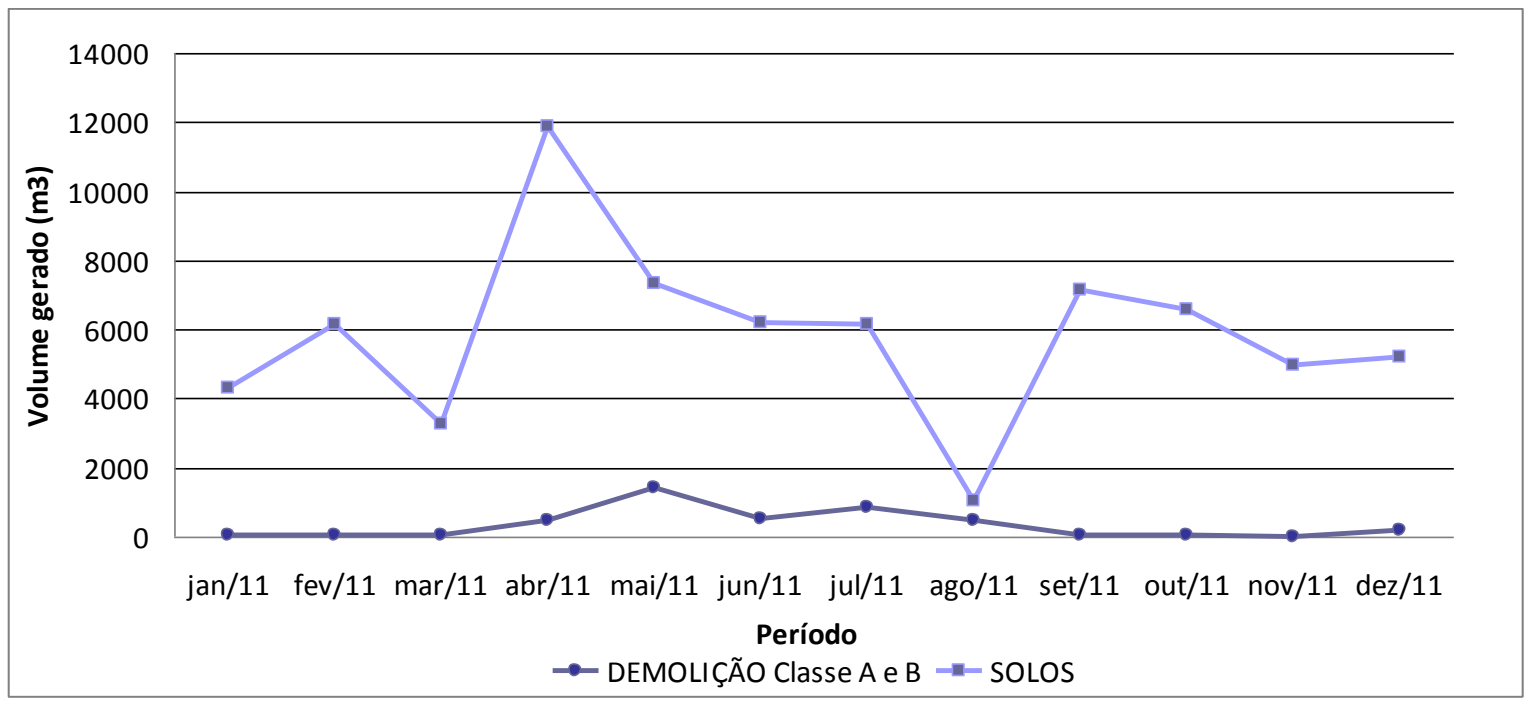

Figura 10. Volume de Resíduos gerados durante Janeiro e Dezembro de 2011. Fonte: Os Autores

Por meio da Figura 10 apresentada pode-se observar que no período compreendido, a magnitude do volume de solo removido foi sempre superior ao volume dos demais tipos de resíduos produzidos uma vez foram realizadas "in loco" predominantemente atividades de escavação e terraplenagem. Entretanto, ressalta-se que no mês de agosto, houve uma redução significativa do volume de solo removido. Tal fato pode ser explicado em função do cronograma da obra, uma vez que foram reduzidas as operações de terraplenagem e escavação neste mês, causando a quase equivalência deste com os volumes de resíduos Classe A e B. A Figura 11 apresenta a distribuição dos resíduos Classe B observados nas obras de demolição e seus volumes mensurados. 


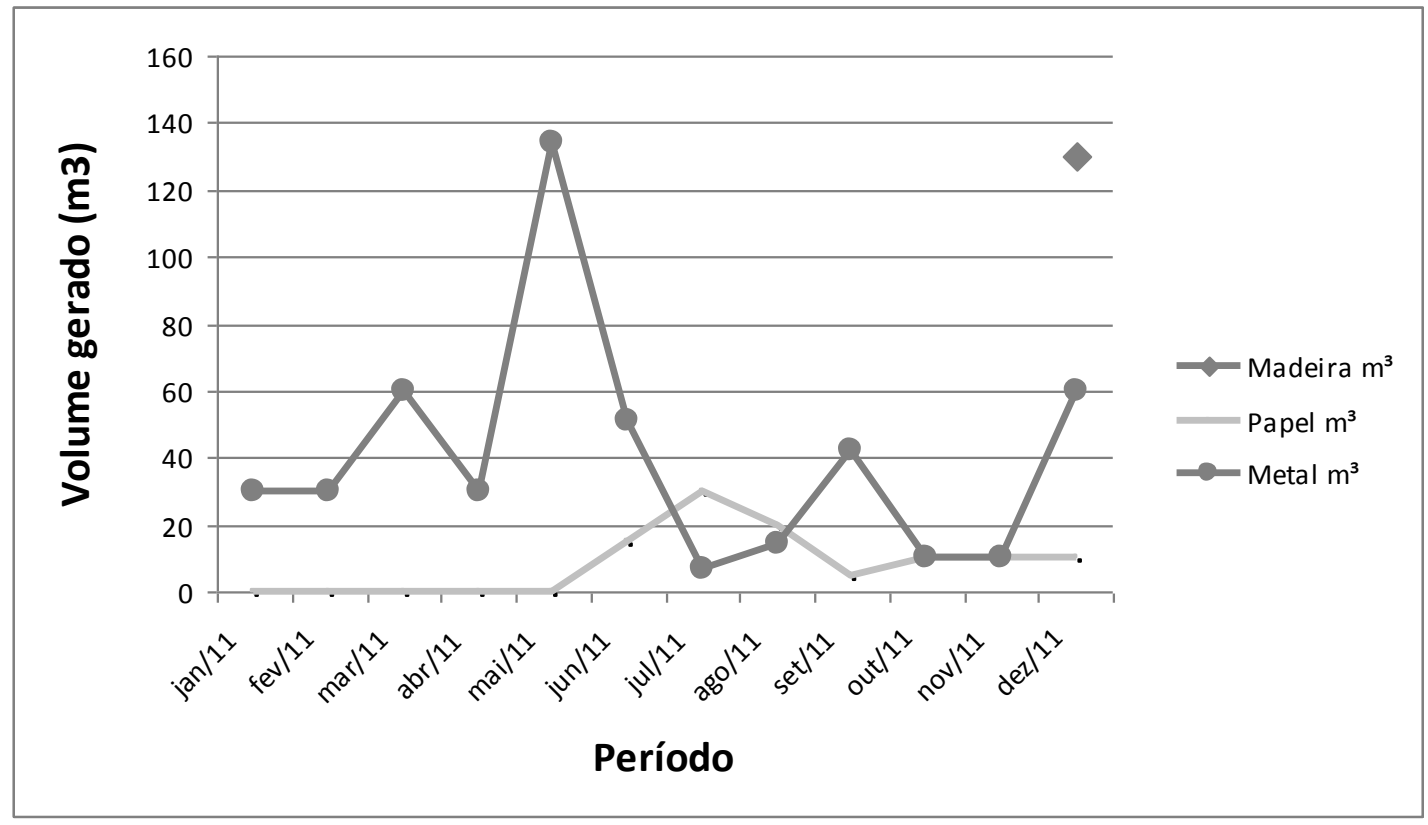

Figura 11- Distribuição do volume de resíduos Classe B. Fonte: Os Autores

Observando-se o gráfico apresentado na Figura 11 pode-se notar que os resíduos Classe B encontrados foram predominantemente: madeira, papel e metal. O máximo volume de madeira removido ocorreu em dezembro de 2011, atingindo um valor aproximado de $130 \mathrm{~m}^{3}$. O volume de metal atingiu seu pico máximo em maio de 2011, ou seja, apresentando um valor próximo a $130 \mathrm{~m}^{3}$ (mesmo valor observado para a madeira). O papel, durante todo o período mensurado, sempre apresentou a menor ocorrência volumétrica quando comparado aos demais resíduos (madeira e metal). O volume de papel máximo atingiu em junho de 2011 aproximadamente 30 $\mathrm{m}^{3}$, ou seja, $23 \%$ do máximo valor observado para os demais resíduos. A Figura 12 apresenta uma comparação entre os volumes de resíduos Classe A e Classe B produzidos entre janeiro e dezembro de 2011.

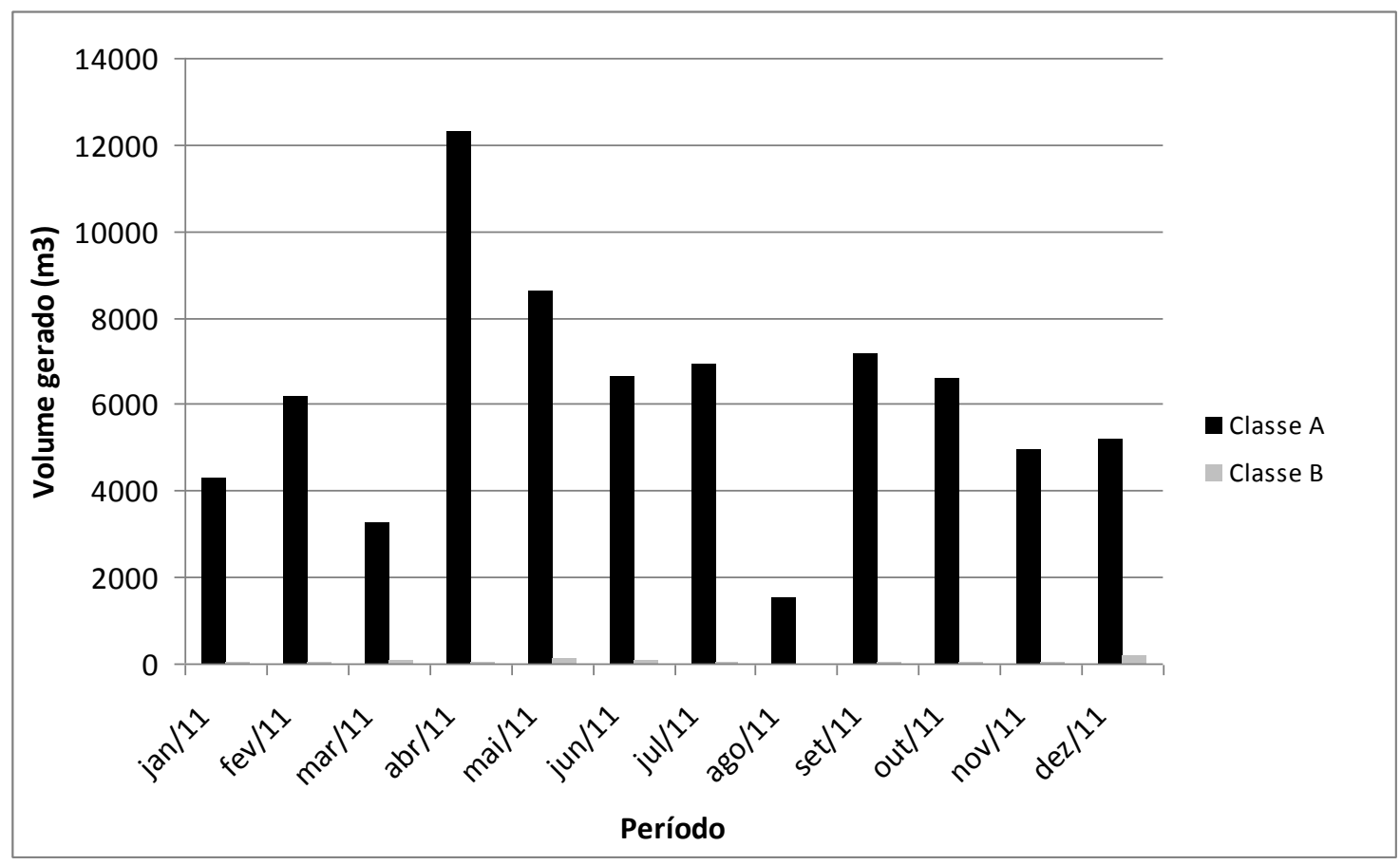

Figura 12 - Comparação entre volumes de resíduos Classe A e Classe B. Fonte: Os Autores 
O gráfico apresentado na Figura 12 demonstra que volume de resíduos Classe A sempre foi superior ao volume de resíduos Classe B. Tal fato pode ser explicado em função dos elevados volumes de gerados pelas obras de escavação e terraplenagem, uma vez que o solo constitui-se em um resíduo Classe A. De uma forma geral, foi produzido um volume total aproximado de resíduos, entre janeiro e dezembro de 2011 de $75.200 \mathrm{~m}^{3}$, somando-se os pertencentes às Classes A e B. Desse volume, salienta-se que a grande parte consistiu em solo removido por meio das operações de terraplenagem. A Tabela 2 a seguir apresenta o percentual de ocorrência de cada tipo de resíduo observado na obra.

Tabela 2. Volumes totais de resíduos produzidos em obra

\begin{tabular}{|c|c|c|}
\hline Tipo de Resíduo & Volume total $\left(\mathrm{m}^{3}\right)$ & Porcentagem de ocorrência \\
\hline Papel & 210 & $0,28 \%$ \\
\hline Madeira & 130 & $0,17 \%$ \\
\hline Metal & 478 & $0,64 \%$ \\
\hline Solo & 70.880 & $94,25 \%$ \\
\hline $\begin{array}{c}\text { Cimentícios (argamassa e } \\
\text { concreto) }\end{array}$ & 3.495 & $4,66 \%$ \\
\hline
\end{tabular}

Fonte: Os Autores

\subsection{Destinação dos resíduos gerados}

De um total de $75.200 \mathrm{~m}^{3}$ de resíduo gerado foram descartados aproximadamente 20.860 $\mathrm{m}^{3}$, o que equivale a $28 \%$ do total produzido. Dessa maneira, entende-se que $72 \%$, o que equivale a $54.340 \mathrm{~m}^{3}$, foram desviados de aterro. A Tabela 3 demonstra os volumes reutilizados e descartados na obra em estudo.

Tabela 3. Volumes totais de resíduos produzidos em obra

\begin{tabular}{|c|c|c|c|c|c|}
\hline Tipo de Resíduo & $\begin{array}{c}\text { Volume total } \\
\left(\mathrm{m}^{3}\right)\end{array}$ & $\begin{array}{c}\text { Volume } \\
\text { reutilizado em } \\
\text { obra }\end{array}$ & $\begin{array}{c}\text { Porcentagem } \\
\text { de volume } \\
\text { reutilizado }\end{array}$ & $\begin{array}{c}\text { Volume } \\
\left.\text { descartado(m }{ }^{3}\right)\end{array}$ & $\begin{array}{c}\text { Porcentagem } \\
\text { de volume } \\
\text { descartado }\end{array}$ \\
\hline Papel & 210 & 0,0 & $0,0 \%$ & 210 & $100 \%$ \\
\hline Madeira & 130 & 0,0 & $0,0 \%$ & 130 & $100 \%$ \\
\hline Metal & 478 & 0,0 & $0,0 \%$ & 478 & $100 \%$ \\
\hline Solo & 70.880 & $51.415,4$ & $72,6 \%$ & $19.464,6$ & $27,4 \%$ \\
\hline $\begin{array}{c}\text { Cimentícios } \\
\text { (argamassa e } \\
\text { concreto) }\end{array}$ & 3.495 & $2.920,8$ & $83,6 \%$ & 574,2 & $16,4 \%$ \\
\hline
\end{tabular}

Fonte: Os Autores

Do volume total de solo removido, aproximadamente $72,6 \%$ foi reaproveitado em obra, 0 restante $(27,4 \%)$ foi destinado para obras localizadas nas proximidades, no intuito deste material ser também nestas reutilizado. Tal situação também ocorreu com os resíduos cimentícios, sendo o volume reutilizado na ordem de $83,6 \%$ do total gerado, o que equivale a $2.920,8 \mathrm{~m}^{3}$. Este material foi reutilizado na obra em estudo principalmente como base ou como reforço do pavimento local. O excedente, aproximadamente $16,4 \%$, foi destinado para reuso em outras obras. Os resíduos correspondentes aos metais, papel e madeira não foram reutilizados na obra, sendo o volume total destes, $818 \mathrm{~m}^{3}$, encaminhado para unidades de reciclagem.

\subsection{Economia gerada pelo manejo dos resíduos produzidos}

Conforme comentado anteriormente, a maior parte dos resíduos gerados pelas operações de demolição consistiu em resíduos de Classe $A$, sendo que o solo se apresentou em maiores 
volumes. Na Tabela 4 são apresentadas estimativas de redução no custo final de deposição do solo em áreas apropriadas e a economia gerada por meio do reuso deste em obra.

Tabela 4. Economia gerada pelo reaproveitamento de solo em obra

\begin{tabular}{|c|c|c|c|c|c|}
\hline $\begin{array}{c}\text { Tipo de } \\
\text { Resíduo }\end{array}$ & $\begin{array}{c}\text { Massa total } \\
\text { gerada } \\
\text { (ton) }\end{array}$ & $\begin{array}{c}\text { Massa de } \\
\text { resíduo } \\
\text { reutilizado } \\
\text { (ton) }\end{array}$ & $\begin{array}{c}\text { Massa de } \\
\text { resíduo } \\
\text { descartado } \\
\text { (ton) }\end{array}$ & $\begin{array}{c}\text { Redução de } \\
\text { custo com } \\
\text { destinação e } \\
\text { deposição final }\end{array}$ & $\begin{array}{c}\text { Economia } \\
\text { devido ao } \\
\text { reuso } \\
\text { (R\$/ton) }\end{array}$ \\
\hline Solo & $85.056,0$ & $61.698,5$ & $23.357,5$ & $27 \%$ & 55,0 \\
\hline
\end{tabular}

De acordo com o apresentado pode-se verificar que o reuso de grande parte do solo removido em obra gerou uma redução no custo de destinação final de $27 \%$ comparando-se a situação em que fosse necessária a destinação de todo volume de solo gerado. O reuso deste material, além de possibilitar menor custo no descarte, também proporcionou uma economia em relação a necessidade de importação de material de jazida natural para execução da regularização topográfica necessária a obra. De acordo com a Tabela 4 nota-se que a economia gerada situou-se em $\mathrm{R} \$ 55,00 /$ tonelada de material utilizado em obra.

Em relação aos materiais cimentícios, uma parte do volume gerado foi reutilizada na própria obra, sendo que a outra foi destinada a áreas apropriadas de descarte ou para obras próximas. A destinação destes materiais ocorreu por meio da utilização de caçambas metálicas cadastradas com capacidade de $5 \mathrm{~m}^{3}$ cada uma. Entretanto, antes da deposição destes materiais nas caçambas foi realizada a segregação destes de forma a separar os resíduos cimentícios de demais heterogeneidades tais como: matéria orgânica e resíduos de outras classes. A Tabela 5 apresenta a quantidade de caçambas utilizadas para o descarte destes resíduos e a economia que se obteve com a segregação preliminar destes antes de serem armazenados nas caçambas e posteriormente destinados aos aterros.

Tabela 5. Redução de custo de caçamba gerado pela segregação de material cimentícios

\begin{tabular}{|c|c|c|c|}
\hline Tipo de Resíduo & $\begin{array}{c}\text { Volume total de } \\
\text { material descartado } \\
\left(\mathrm{m}^{3}\right)\end{array}$ & $\begin{array}{c}\text { Quantidade de } \\
\text { caçambas de material } \\
\text { descartado }\end{array}$ & $\begin{array}{c}\text { Economia com } \\
\text { segregação de material } \\
\text { em caçamba } \\
\left(\mathrm{R} \$ / \mathrm{m}^{3}\right)\end{array}$ \\
\hline Cimentícios & 574,2 & 115 & 44,00 \\
\hline \multicolumn{2}{|r}{} & Fonte: Os Autores
\end{tabular}

Observando-se as informações apresentadas na Tabela 5 nota-se que foram utilizadas 115 caçambas para o descarte dos resíduos de materiais cimentícios gerados pelas obras de demolição. Percebe-se também que a economia com a segregação dos materiais preliminarmente ao seu descarte possibilitou uma economia de $\mathrm{R} \$ 44,00 / \mathrm{m}^{3}$. Tal fato pode ser explicado uma vez que a empresa transportadora da caçamba cobra um adicional de $42 \%$ em cada caçamba que contenha material heterogêneo. Dessa forma, a simples operação de segregação dos resíduos antes de sua deposição final conduziu a uma economia significativa.

A porção de resíduos cimentícios que não foi destinada à aterros foi reutilizada em obra na execução de camadas de base de pavimento e na confecção de argamassa e concreto não estrutural. Conforme anteriormente apresentado, para possibilitar este reuso, os resíduos foram britados em uma usina móvel instalada no canteiro de obras. A Tabela 6 apresenta a economia gerada pela reciclagem e reuso destes resíduos na obra em estudo. 
Tabela 6. Redução de custo com reciclagem e reutilização em obra

\begin{tabular}{|c|c|c|c|}
\hline Tipo de Resíduo & $\begin{array}{c}\text { Volume total de } \\
\text { material reutilizado } \\
\left(\mathrm{m}^{3}\right)\end{array}$ & $\begin{array}{c}\text { Quantidade de } \\
\text { caçambas de material } \\
\text { reutilizado }\end{array}$ & $\begin{array}{c}\text { Economia com } \\
\text { reciclagem e } \\
\text { reutilização em obra } \\
\left(\mathrm{R} \$ / \mathrm{m}^{3}\right)\end{array}$ \\
\hline Cimentícios & 2920,8 & 584 & 55,00 \\
\hline
\end{tabular}

Por meio da Tabela 6 nota-se que ao total foi reutilizado um volume de 2920,8 m3 de resíduos cimentícios, o que equivaleria a necessidade de 584 caçambas caso este volume fosse descartado. Verifica-se também que a economia com a reciclagem e o reuso deste resíduo em obra conduziu a um valor equivalente a $\mathrm{R} \$ 55,0 / \mathrm{m} 3$. Ressalta-se que para este cálculo foi considerada a não necessidade de transporte para aterro, a mobilização da usina móvel na obra e a redução da necessidade de aquisição de matéria prima virgem que foi substituída pelo agregado reciclado.

Apesar de a maior parte dos resíduos gerados pelas operações de demolição consistir em resíduos Classe $A$, também foi verificado um volume expressivo de resíduos Classe $B$ composto basicamente por madeira, metal e papel. Em relação a madeira, toda esta foi descartada em aterros adequados. Contudo os demais resíduos, ou seja, papel e metais, foram vendidos para empresas recicladoras. A Tabela 7 apresenta o ganho econômico gerado por esta prática.

Tabela 7. Redução de custo com segregação e reciclagem de metais

\begin{tabular}{|c|c|c|}
\hline Tipo de Resíduo & Volume total de descartado (m3) & $\begin{array}{c}\text { Ganho total } \\
\mathrm{R} \$ / \mathrm{kg} \\
\text { (segregação + reciclagem) }\end{array}$ \\
\hline Metais & 478 & 2,5 \\
\hline Papel & 210 & 0,20 \\
\hline
\end{tabular}

Os resíduos de metal e papelão também foram acondicionados em obra e posteriormente transportados para as empresas de reciclagem por meio de caçambas metálicas registradas. Da mesma maneira que o ocorrido com os resíduos cimentícios, o custo da caçamba variou com o grau de heterogeneidade do material nela armazenado, dessa forma, foi novamente tomado o procedimento da segregação dos resíduos antes de acondicioná-los nas caçambas. O volume total descartado foi equivalente a 138 caçambas com capacidade de $5 \mathrm{~m}^{3}$. Dessa maneira, o ganho total com cada resíduo foi de $R \$ 2,50 / \mathrm{kg}$ de metal e $R \$ 0,20 / \mathrm{kg}$ de papel. Foram considerados nestes cálculos a economia gerada pela segregação dos materiais e o preço de compra praticado pelas empresas de reciclagem que adquiriram os resíduos, além do custo de transporte a áreas adequadas de descarte.

\section{CONCLUSÃO} conclusões:

Com base na argumentação exposta neste artigo podem ser tomadas as seguintes

a) O setor da construção civil destaca-se atualmente como um grande gerador de resíduos sólidos dentre os demais setores econômicos. Os resíduos de construção e demolição gerados por este setor compõem grandes percentuais na massa de resíduos sólidos urbanos (RSU) gerados em diversos municípios brasileiros. Este fato pode ser atribuído à expansão que deste ramo da economia, à necessidade constante de matéria prima, ao grande desperdício durante as 
obras e à falta de políticas públicas e objetivas que considerem esta situação como um problema a ser resolvido. Dessa maneira, este trabalho ressalta a importância da adoção, por parte do setor de construção civil, de práticas de sustentabilidade que reduzam a necessidade de consumo de matéria-prima e que otimize os processos produtivos no intuito de se reduzir o volume de desperdícios e, por conseqüência, a geração de resíduos.

b) A reutilização de resíduos gerados pela construção civil consiste em uma importante ação de sustentabilidade, pois reduz por meio da reciclagem e reuso destes, os volumes gerados por este setor. A geração de subprodutos, originados por esta logística, permite também a utilização racional dos insumos de construção, permitindo maior eficiência de utilização (uma vez que mitiga desperdícios em obra) e reduz a necessidade de matéria prima causando um menor impacto no meio ambiente.

c) Os resíduos gerados na obra em estudo foram predominantemente do tipo Classe $A$, sendo sua destinação final de acordo com o preconizado pela resolução $n^{\circ} 307$ do $\operatorname{CONAMA}(2002,2004)$. Grande parte dos resíduos gerados foi reutilizada em obra, o que possibilitou a redução da necessidade de matéria prima e volume de transporte. Dessa forma, pode-se afirmar que a prática de reciclagem utilizada na obra em estudo consistiu em um exemplo de prática de sustentabilidade na construção civil.

d) A utilização de ferramentas de gestão e manejo dos resíduos de demolição gerados pela obra em estudo conduziu a ganhos econômicos significativos uma vez que foram reduzidos os custos envolvidos no transporte e descarte destes resíduos bem como na redução da necessidade de aquisição de matéria prima virgem para a realização de algumas fases da obra

\section{AGRADECIMENTOS}

Os autores agradecem o apoio recebido das seguintes instituições: Programa de Mestrado em Gestão Ambiental e Sustentabilidade (GeAs/Uninove), Universidade Nove Julho, W. Torre Engenharia e Construções S.A e ao Gerente de Qualidade e Meio Ambiente João Cabrera Neto.

\section{REFERÊNCIAS}

ABNT - ASSOCIAÇÃO BRASILEIRA DE NORMAS TÉCNICAS. NBR 10004: Resíduos Sólidos Classificação. Rio de Janeiro, 2004.

ABRELPE - Associação Brasileira de Empresas de Limpeza Pública e Resíduos Especiais. Panorama dos Resíduos Sólidos no Brasil, São Paulo, Brasil, 116p, 2012.

ANGULO, S. C., TEIXEIRA, C. E., CASTRO, A. L., \& NOGUEIRA, T. P. Resíduos de construção e demolição: avaliação de métodos de quantificação. Engenharia Sanitaria e Ambiental , v.16, n. 3, pp. 299-306. 2011

ASSUNÇÃO, L. T., CARVALHO, G. F., \& BARATA, M. S. Avaliação das propriedades das argamassas de revestimento produzidas com resíduos da construção e demolição como agregado. Exacta , 5 (2), pp. 223-230. 2007

CONAMA. CONSELHO NACIONAL DO MEIO AMBIENTE. Resolução n‥ 431, de 25 de maio de 2011. Altera o $\operatorname{art.~}^{\circ}$ da Resolução $n^{\circ} 307$, de 5 de julho de 2002, do Conselho Nacional do Meio Ambiente- CONAMA, estabelecendo nova classificação para o gesso. Diário Oficial da União, Brasília, DF. Disponível em: <http://www.mma.gov.br/port/conama/-index.cfm>. 
CONAMA. CONSELHO NACIONAL DO MEIO AMBIENTE. Resolução no. 348, de 16 de agosto de 2004. Altera a resolução CONAMA $n^{\circ} 307$ de 5 de julho de 2002, incluido amianto na classe de resíduos perigosos. Diário Oficial da União, Brasília, DF. Disponível em: <http://www.mma.gov.br/port/conama/-index.cfm>.

CONSELHO NACIONAL DO MEIO AMBIENTE - CONAMA: Resolução no. 307, de 05 de julho de 2002. Estabelece diretrizes, critérios e procedimentos para a gestão dos resíduos da construção civil. Diário Oficial da União, Brasília, DF, 17 de julho de 2002. Disponível em: <http://www.mma.gov.br/port/conama/-index.cfm>.

FERRAZ, A. L., \& SEGANTINI, A. A. Engenharia Sustentável: Aproveitamento de resíduos de. Anais do $5^{\circ}$ Encontro de Energia no Meio Rural. Campinas. 2004.

JOHN, V. M.; AGOPYAN, V. Reciclagem de resíduos da construção civil. In: SEMINÁRIO RECICLAGEM DE RESÍDUOS SÓLIDOS DOMICILIARES. Secretaria de Estado do Meio Ambiente. São Paulo, 2000. 13p.

MELO, A., GONÇALVES, A., \& MARTINS, I. Construction and demolition waste generation and management in Lisbon (Portugal). Resources, Conservation and Recycling, v. 15 n.55, pp. 12521264, 2011.

NUNES, K., MAHLER, C., \& VALLE, R. Reverse logistics in the Brazilian construction industry. Journal of Environmental Management (90), p 3717-3720. 2009

PASCHOALIN FILHO, J, A; GRAUDENZ, G, S. Destinação irregular de resíduos de construção e demolição (RCD) e seus impactos na saúde coletiva. Revista de Gestão Social e Ambiental, v.6, n.1, p 127-142, 2012.

RICCl, G. Estudo das características mecânicas do concreto compactado com rolo com agregados reciclados de construção e demolição para pavimentação. Dissertação de Mestrado, Universidade de São Paulo, Escola Politécnica, São Paulo. 2007

SANTOS, E. C. Aplicação de resíduos de construção e demolição reciclados (RCD-R) em estruturas de solo reforçado. Dissertação de Mestrado, Universidade de São Paulo, Escola de Engenharia, São Carlos. 2007.

SEGANTINI, A, A, S; WADA, P, H. Estudo de dosagem de tijolos de solo-cimento com adição de resíduos de construção e demolição. Acta Scientarum Technology, V.33, n.2, p.179-183, 2011.

SINDUSCON/SP- Sindicato da Indústria da Construção Civil do Estado de São Paulo. Resíduos de Construção Civil e o Estado de São Paulo. Secretaria de Estado do Meio Ambiente, Governo do Estado de São Paulo. São Paulo, 120p, 2012.

SILVA, V, A; FERNANDES, A, L. Cenário do gerenciamento dos resíduos da construção e demolição (RCD) em Uberaba-MG. Revista Sociedade \& Natureza, v.24, n.2, p. 333-344, 2012.

SOUZA, Márcia I. B.; SEGANTINI, Antônio A. S. e PEREIRA, Joelma A. Tijolos prensados de solo-cimento confeccionados com resíduos de concreto. Revista Brasileira de Engenharia Agrícola e Ambiental, v.12, n.2, 2008

SHNEIDER, D.M. (2003). Deposições irregulares de resíduos da construção civil na cidade de São Paulo. 2003. 131p Dissertação (mestrado). Universidade de São Paulo, Escola Politécnica da Universidade de São Paulo, São Paulo.

TAM, V. W.Y.; TAM, C. M. A review on the viable technology for construction waste recycling. Resources, Conservation and Recycling. V. 47, p. 209-221, 2006. 
ULSEN, C.; KAHN, H.; ÂNGULO, S, C; JOHN, V, M. Chemical composition of mixed construction and demolition recycled aggregates from the State of São Paulo. Revista de Escola de Minas, v.63, n.2, p.339-346, 2010.

VIEIRA, G. L., \& MOLIN, D. C. Viabilidade técnica da utilização de concretos com agregados reciclados de resíduos de construção e demolição. Ambiente Construído , 4 (4), p 47-63. 2004 